\title{
Gender Differences in Suicidal Ideation and Related Factors among North Korean Refugees in South Korea
}

\author{
Jin-Won Noh', Hyunchun Park², Young Dae Kwon³, In Hye Kim², \\ Yo Han Lee ${ }^{4}$, Yoon Jung Kim ${ }^{5}$, and Sin Gon Kim ${ }^{6}$ \\ 'Department of Healthcare Management and Institute of Global Healthcare Research, Eulji University, Seongnam, Republic of Korea \\ ${ }^{2}$ Department of Healthcare Management, Eulji University, Seongnam, Republic of Korea \\ ${ }^{3}$ Department of Humanities and Social Medicine, College of Medicine and Catholic Institute for Healthcare Management, \\ the Catholic University of Korea, Seoul, Republic of Korea \\ ${ }^{4}$ Department of Public Healthcare Services, Seoul Bukbu Hospital, Seoul, Republic of Korea \\ ${ }^{5}$ Division of Endocrinology and Metabolism, Department of Internal Medicine, Hallym University Hangang Sacred Heart Hospital, Seoul, \\ Republic of Korea \\ ${ }^{6}$ Division of Endocrinology and Metabolism, Department of Internal Medicine, Korea University College of Medicine, Seoul, Republic of Korea
}

Objective According to previous social survey, a high number of North Korean refugees (NKRs) in South Korea had suicidal ideation. The purpose of this study is to examine the related factors for suicidal ideation among NKRs by gender in South Korea.

Methods We examined the sample of NKRs, 701 subjects (men=160, women=-541) residing in South Korea, the participants were enrolled from October 2008 to May 2014. The related factors with suicidal ideation in NKRs were analyzed via a logistic regression analysis.

Results Refugee women were more likely to have suicidal ideation than men were. Although thoughts of suicide do not necessarily mean that they will follow through, however, there is an association that the higher rate of suicide also results in a higher rate of attempted suicide. In both genders, they tended to think more frequently about suicide who had stayed in South Korea for more than 5 years. In addition, higher frequencies of suicidal ideation also associated with higher level of perceived stress in both genders.

Conclusion The gender difference should be addressed when designing suicide prevention interventions among the North Korean population in South Korea.

Psychiatry Investig 2017;14(6):762-769

Key Words North Korean refugees, Suicidal ideation, Gender differences.

\section{INTRODUCTION}

North Korean refugees (NKRs) undergo internal and external upheaval during the period after leaving North Korea and resettlement in South Korea. In addition to leaving their own homes and families, NKRs are asked to adapt to South Korean society. During these processes, NKRs experience high levels of stress, which can lead to maladjustment. There has been increased public concern for these individuals, because some cases of maladjustment have ended in extreme consequenc-

Received: September 6, 2016 Revised: December 29, 2016

Accepted: March 25, 2017 Available online: September 29, 2017

$\triangle$ Correspondence: Sin Gon Kim, MD, PhD

Division of Endocrinology and Metabolism, Department of Internal Medicine,

Korea University College of Medicine, 73 Inchon-ro, Seongbuk-gu, Seoul 02841,

Republic of Korea

Tel: +82-2-920-5890, Fax: +82-2-953-9355, E-mail: k50367@korea.ac.kr

(a) This is an Open Access article distributed under the terms of the Creative Commons Attribution Non-Commercial License (http://creativecommons.org/licenses/bync/4.0) which permits unrestricted non-commercial use, distribution, and reproduction in any medium, provided the original work is properly cited. es, including suicide..$^{1-3}$ According to the 2014 North Korean refugees' social survey, conducted by the Korea Hana Foundation, one-fifth $(20.5 \%)$ of respondents reported that they had suicidal ideation during the past year. ${ }^{3}$ This rate is approximately three times higher than that among South Koreans (6.8\%), according to the report of the 2014 Social Survey. ${ }^{4}$ According to 2012 Korea National Police Agency data, the NKR suicide rate was $11.7 \%$, nearly double the rate among South Koreans (5.75\%). These data suggest that suicide is a serious problem among NKRs.

Previous studies of other immigrants showed that higher rates of suicidal ideation among refugees have been reported, despite the fact that immigration leads to a wealthier life than that experienced by refugees in their home countries. Several previous studies have investigated the reasons for the higher rate of suicidal ideation among refugees versus the host population. ${ }^{5-9}$ First, there is a perspective that the high rate of suicidal ideation among refugees originates from post-traumatic 
stress disorder (PTSD) or depression related to negative experiences associated with exile and resettlement. ${ }^{6-9}$ In contrast, other study has suggested that PTSD and depression had no association with suicidal ideation. ${ }^{5}$ Also, other studies suggest that emigration itself is a traumatic experience, akin to "the roots of their lives being removed," causing augmentation of the normal stress experience that leads to suicidal ideation or attempts. $^{7-10}$

Previous study of suicidal ideation among NKRs investigated the factors related to suicidal ideation, but only limited to small number of North Korean refugee women. ${ }^{11}$ The study found that the stress of daily life was a risk factor for suicidal ideation; however, this study was limited to women, and not representative of the whole NKR population. And other important factors of mental health, such as depression, showed no significant association with suicidal ideation, suggesting the need for further investigation. There is a need to examine gender differences in suicidal ideation and related factors among NKRs in South Korea because some previous studies showed gender differences in relation to these factors. ${ }^{12,13}$

The purpose of this study was to examine the factors related to suicidal ideation among NKRs in South Korea by gender, addressing the limitations of small sample sizes in previous studies, and to provide baseline data for developing interventions for suicide prevention.

\section{METHODS}

\section{Study population}

A sample of NKRs, 30 years or older and residing in Seoul, participated voluntarily in this study. In total, 721 subjects participated from October 2008 to May 2014. Health questionnaire surveys and medical examinations were conducted once per month with the help of the Hana Center (a representative welfare center supported by the Korean government to assist NKRs in South Korea). A detailed protocol and description of related methods for the present study have been reported previously. ${ }^{14}$ Approval of the study was obtained from the Institutional Review Board of Korea University Medical Center (approval number: ED08023). In addition, all participants provided a written informed consent.

\section{Variables}

Suicidal ideation was defined as a positive response to the following question: "During the past year did you ever seriously consider attempting suicide?" If the answer was 'yes', then the respondent was considered to have suicidal ideation.

To investigate factors related to suicidal ideation among NKRs by gender, factors were categorized as demographic characteristics (age and number of family members), socioeconomic fac- tors (education level, employment status, duration of stay in South Korea), and health-related factors [body mass index (BMI), alcohol drinking, smoking status, daily perceived stress levels, previously diagnosed with chronic diseases and having depressive symptoms].

Analyses were performed by gender and were adjusted for the following covariates: age (younger than 40,40 s, 50s, older than 60), number of family members (single person families, more than two members), education level in North Korea (high school or below, college or above), employment status (yes, no), duration of stay in South Korea (less than 5 years, more than 5 years), BMI (underweight, BMI $<18.5$; normal, $\mathrm{BMI}=18.5-22.9$; overweight, $\mathrm{BMI}=23-24.9$; obese, $\mathrm{BMI}>25$ $\mathrm{kg} / \mathrm{m}^{2}$ ). Alcohol drinking behavior was categorized as drinker or non-drinker according to following question: "Do you have experience of drinking more than one glass of alcohol?" Smoking status was categorized as smoker (current/ex-smoker) or non-smoker (never smoker) based on the following question: "What is the total number of cigarettes you have smoked in your lifetime?" If the subject answered 'never smoked, he/ she was categorized as a non-smoker. If the subject answered 'fewer than 5 packs' or 'more than 5 packs', the subject was categorized as a smoker. Perceived stress level was measured as very high ( 4 points), high ( 3 points), moderate ( 2 points), or low (1 point), according to the following question, "On average days, are you stressed?"

We included 11 chronic diseases (hypertension, diabetes mellitus, mental and behavioral disorders, respiratory tuberculosis, cardiovascular disease, cerebrovascular disease, nervous system disease, malignant neoplasm, thyroid dysfunction, liver disease, and chronic renal failure). If participant was previously diagnosed with more than one of these diseases, he/ she was considered to be previously diagnosed with chronic diseases.

For identifying depression, the Korean edition of the Center for Epidemiological Studies Depression Scale (CES-D) with 20 items was administered. ${ }^{15}$ Each item was scored on a 4-point scale, from 0 (rarely) to 3 (most of the time). The score of each item is added up for the total score, with higher scores indicating more severe depressive symptoms. The CES-D cutoff score, 21 or above, was defined as having depression.

We tried to enhance the quality and completeness of the surveys by having subjects engage in a one-to-one interview with a doctor who had escaped from North Korea.

\section{Statistical analysis}

The STATA software (ver. 13.1; StataCorp, College Station, TX, USA) was used for all analyses. Frequency and descriptive statistics were assessed with regard to demographic, socioeconomic, and health-related characteristics. We also tested 
whether basic assumptions for inferential statistical techniques were satisfied. Differences in distributions among general characteristics according to gender were tested via t-tests and ANOVA. Associations with suicidal ideation were analyzed via a logistic regression analysis. Correlation analyses were used to assess initial relationships between the study variables, and no issue with multicollinearity was found. Twenty subjects were excluded from the full analyses because of missing data.

\section{RESULTS}

\section{General characteristics and suicidal ideation in North Korean refugees}

Sociodemographic and health-related characteristics were shown in Table 1. The sample consisted of 701 NKRs in South Korea (77.2\% women). Approximately two-thirds (65.1\%) had education level of high school or below, approximately twofifths (41.5\%) were unemployed, and one third (33.2\%) were single-person families. Among respondents, about 52.5\% reported their BMI status as normal weight, and two-thirds had been in South Korea for less than 5 years. About 32.5\% were non-drinkers, and 76.5\% were non-smokers. Approximately half $(47.4 \%)$ reported that they had high or very high levels of stress. The prevalences of having chronic diseases and depression were $38.1 \%$ and $62.5 \%$, respectively.

Table 2 shows the results of t-tests and ANOVA comparing the rates of suicidal ideation according to demographic characteristics, socioeconomic factors, and health-related factors by gender. Women $(25.9 \%)$ tended to think more frequently about suicide than men (14.7\%). In both genders, they were more likely to think about suicide if they had been in South Korea for more than 5 years. A higher level of perceived stress was also associated with higher frequencies of suicidal ideation in both genders. Among NKR women who were smokers, having chronic diseases or depression, had thought about suicide more frequently.

\section{Gender differences in factors associated with suicidal ideation among North Korean refugees}

For men, more frequent thoughts about suicide were observed in the highly stressed group (OR 4.21, 95\%CI 0.98-18.10) and very highly stressed groups (OR 10.79, 95\%CI 1.61-72.19) versus the minimally stressed group. Suicidal ideation in women was also more frequent for those who reported a high level of stress (OR 14.48, 95\%CI 1.82-115.20), and a very high level of stress (OR 29.13, 95\%CI 3.49-243.33) versus the minimally stressed group. NKR women who had been in South Korea for more than 5 years (OR 1.92, 95\%CI 1.01-3.64), suffering from chronic diseases (OR 2.62, 95\%CI 1.40-4.93) and having depression (OR 1.91, 95\%CI 1.01-3.63) also had higher risk of suicidal ideation (Table 3). In contrast to women, the coexistence of chronic diseases, having depression, and duration of stay in South Korea were not associated with suicidal ideation among NKR men in multiple logistic regression analyses.

\section{DISCUSSION}

In this study, we examined the factors related to suicidal ideation among NKRs in South Korea by gender. Among respondents, one-fourth (23.3\%) reported that they had suicidal ideation. This result is similar to findings from the 2014 North Korean Refugees' Social Survey (20.5\%). The rate of suicidal ideation among North Korean refugees was three times more than that among the general South Korean population and the completed suicide rate was double that of the general South Korean population. Although suicidal ideation does not necessarily lead to a completed suicide, a higher rate of suicidal ideation is associated with a higher rate of suicide attempts. Thus, this higher rate of suicidal ideation among the NKR population needs to be taken seriously. ${ }^{16}$

In our study, refugee women were more likely to have suicidal thoughts than refugee men. For men, the stress level in daily life was the only variable associated with suicidal ideation. However, for women, several factors were associated with suicidal ideation, consistent with previous findings. ${ }^{12,17,18}$ Previous study examined gender difference in suicidal ideation among the general South Korean population and showed that the higher prevalence of suicidal ideation among women as compared to men which could be explained by the fact that women tended to have lower levels of income and a poorer mental health status, such as a higher prevalence of depression, as compared to men. ${ }^{12,13}$ However, previous studies of other populations reported no gender difference in suicidal ideation, indicating that other social and cultural aspects may have contributed to suicidal ideation. ${ }^{19,20}$ The gender differences in suicidal ideation among NKRs suggest the need for a nuanced approach to mental healthcare for the North Korean refugee population in South Korea.

The results of our study showed that high levels of stress lead to a greater probability of suicidal thoughts in both genders. This is consistent with a previous study suggesting that daily stressors are more negatively augmented among refugees. ${ }^{7}$ Another study suggested that suicide could function as an escape mechanism for avoiding stressful situations. ${ }^{21}$ Regarding the OR value of highly stressed and very highly stressed groups versus the minimally stressed group, refugee women had higher OR values than men, indicating a stronger association between daily stress levels and suicidal ideation.

Refugee women were more affected by a greater number of factors related to suicidal ideation than men. In our cohort, ref- 
ugee women who have been diagnosed with chronic diseases were more likely to have suicidal ideation, consistent with results from South Korean women. ${ }^{22}$ According to a previous study, the prevalence of chronic diseases among NKRs differed significantly by gender. ${ }^{23}$ The study showed that the proportion of refugee women suffering from cardiovascular disease

Table 1. Sociodemographic and health-related characteristics of the NKRs

\begin{tabular}{|c|c|c|c|c|}
\hline & Total $(\mathrm{N}=701)$ & $\operatorname{Men}(\mathrm{N}=160)$ & Women $(\mathrm{N}=541)$ & \multirow{2}{*}{$\mathrm{F}(\mathrm{t})$} \\
\hline & $\mathrm{N}(\%)$ & $\mathrm{N}(\%)$ & $\mathrm{N}(\%)$ & \\
\hline Age & & & & $8.17^{* *}$ \\
\hline$<40$ & $284(40.6)$ & $50(31.5)$ & $234(43.3)$ & \\
\hline $40 s$ & $218(31.2)$ & $57(35.9)$ & $161(29.8)$ & \\
\hline $50 \mathrm{~s}$ & $99(14.1)$ & $23(14.5)$ & $76(14.0)$ & \\
\hline$\geq 60$ & $99(14.1)$ & $29(18.2)$ & $70(12.9)$ & \\
\hline Family & & & & 1.95 \\
\hline Single person & $233(33.2)$ & $43(26.9)$ & $190(35.1)$ & \\
\hline$\geq 2$ members & $468(66.8)$ & $117(73.1)$ & $351(64.9)$ & \\
\hline Education (NK) & & & & 1.65 \\
\hline High school or less & $423(65.1)$ & $86(59.3)$ & $337(66.7)$ & \\
\hline More than a college & $227(34.9)$ & $59(40.7)$ & $168(33.3)$ & \\
\hline Employed & & & & $-2.43^{* *}$ \\
\hline No & $261(41.5)$ & $71(50.3)$ & $190(38.9)$ & \\
\hline Yes & $368(58.5)$ & $70(49.7)$ & $298(61.1)$ & \\
\hline Duration of stay (SK) & & & & 1.28 \\
\hline$<5$ years & $479(68.3)$ & $106(66.3)$ & $373(68.9)$ & \\
\hline$\geq 5$ years & $222(31.7)$ & $54(33.7)$ & $168(31.1)$ & \\
\hline BMI & & & & $4.19^{*}$ \\
\hline Underweight & $26(3.8)$ & $6(4.0)$ & $20(3.7)$ & \\
\hline Normal & $361(52.5)$ & $66(43.4)$ & $295(55.1)$ & \\
\hline Overweight & $162(23.6)$ & $44(29.9)$ & $118(22.1)$ & \\
\hline Obese & $138(20.1)$ & $36(23.7)$ & $102(19.1)$ & \\
\hline Drinking & & & & $6.80^{* * *}$ \\
\hline Non-drinker & $201(32.5)$ & $14(9.9)$ & $187(29.3)$ & \\
\hline Drinker & $417(67.5)$ & $128(90.1)$ & $289(60.7)$ & \\
\hline Smoking & & & & $25.85^{* * *}$ \\
\hline Non-smoker & $431(76.5)$ & $30(21.7)$ & $401(94.4)$ & \\
\hline Smoker & $132(23.5)$ & $108(78.3)$ & $24(5.6)$ & \\
\hline Stress & & & & $7.13^{* *}$ \\
\hline Low & $66(9.6)$ & $18(11.5)$ & $89(16.7)$ & \\
\hline Moderate & $296(43.0)$ & $41(26.3)$ & $179(33.6)$ & \\
\hline High & $220(31.9)$ & $78(50.0)$ & $218(40.9)$ & \\
\hline Very high & 107 (15.5) & $19(12.2)$ & $47(8.8)$ & \\
\hline Chronic diseases & & & & -1.29 \\
\hline No & $434(61.9)$ & $106(66.2)$ & $328(60.6)$ & \\
\hline Yes & $267(38.1)$ & $54(33.8)$ & $213(39.4)$ & \\
\hline Depression & & & & $-3.45^{* *}$ \\
\hline No & $261(37.2)$ & $63(39.4)$ & $198(36.6)$ & \\
\hline Yet & $440(62.8)$ & $97(60.6)$ & $343(63.4)$ & \\
\hline
\end{tabular}

${ }^{*} \mathrm{p}<0.05,{ }^{* *} \mathrm{p}<0.01,{ }^{* * *} \mathrm{p}<0.001$. BMI: body mass index, NK: North Korea, SK: South Korea, NKRs: North Korean refugees 
Table 2. Rates of suicidal ideation according to variables by gender

\begin{tabular}{|c|c|c|c|c|c|c|}
\hline & \multicolumn{3}{|c|}{ Men } & \multicolumn{3}{|c|}{ Women } \\
\hline & \multirow{2}{*}{$\mathrm{N}$} & \multicolumn{2}{|c|}{ Suicidal ideation } & \multirow{2}{*}{$\mathrm{N}$} & \multicolumn{2}{|c|}{ Suicidal ideation } \\
\hline & & $\mathrm{N}(\%)$ & $\mathrm{t} / \mathrm{F}$ & & $\mathrm{N}(\%)$ & $\mathrm{t} / \mathrm{F}$ \\
\hline Total & 150 & $22(14.7)$ & & 506 & $131(25.9)$ & \\
\hline Age & & & 0.33 & & & 0.12 \\
\hline$<40$ & 49 & $7(14.3)$ & & 220 & $56(25.5)$ & \\
\hline $40 \mathrm{~s}$ & 55 & $9(16.4)$ & & 149 & $41(27.5)$ & \\
\hline $50 \mathrm{~s}$ & 20 & $3(15.0)$ & & 71 & $17(23.9)$ & \\
\hline$\geq 60$ & 25 & $2(8.0)$ & & 66 & $17(25.8)$ & \\
\hline Family & & & -1.11 & & & -0.44 \\
\hline Single-person & 42 & $4(9.5)$ & & 178 & $44(24.7)$ & \\
\hline$\geq 2$ members & 108 & $18(16.7)$ & & 328 & $87(26.5)$ & \\
\hline Education (NK) & & & 0.06 & & & 0.98 \\
\hline High school or less & 82 & $12(14.6)$ & & 320 & $83(25.9)$ & \\
\hline More than college & 56 & $8(14.3)$ & & 156 & $34(21.8)$ & \\
\hline Employed & & & -0.45 & & & 0.95 \\
\hline No & 67 & $9(13.4)$ & & 178 & $50(28.1)$ & \\
\hline Yes & 68 & $11(16.2)$ & & 282 & $68(24.1)$ & \\
\hline Duration of stay (SK) & & & $-2.05^{*}$ & & & $-2.00^{*}$ \\
\hline$<5$ years & 103 & $11(10.7)$ & & 348 & $81(23.3)$ & \\
\hline$\geq 5$ years & 47 & $11(23.4)$ & & 158 & $50(31.7)$ & \\
\hline BMI & & & 1.60 & & & 0.23 \\
\hline Underweight & 5 & $0(0)$ & & 19 & $6(31.6)$ & \\
\hline Normal & 64 & $9(14.1)$ & & 275 & $69(25.1)$ & \\
\hline Overweight & 40 & $3(7.5)$ & & 112 & $31(27.7)$ & \\
\hline Obese & 34 & $8(23.5)$ & & 94 & $23(24.5)$ & \\
\hline Drinking & & & 0.04 & & & -1.27 \\
\hline Non-drinker & 14 & $2(14.3)$ & & 171 & $40(23.4)$ & \\
\hline Drinker & 122 & $17(14.0)$ & & 277 & $80(28.9)$ & \\
\hline Smoking & & & -0.68 & & & $-2.18^{*}$ \\
\hline Non-smoker & 29 & $3(10.3)$ & & 389 & $91(23.4)$ & \\
\hline Smoker & 104 & $16(15.4)$ & & 23 & $10(43.5)$ & \\
\hline Stress & & & $9.66^{* * *}$ & & & $47.57^{* * *}$ \\
\hline Low & 17 & $0(0)$ & & 46 & $1(2.2)$ & \\
\hline Moderate & 77 & $4(5.2)$ & & 209 & $20(9.6)$ & \\
\hline High & 39 & $11(28.2)$ & & 166 & $55(33.1)$ & \\
\hline Very high & 16 & $7(43.8)$ & & 82 & $53(64.6)$ & \\
\hline Chronic diseases & & & 0.09 & & & $-7.51^{* * *}$ \\
\hline No & 101 & 15 (14.9) & & 303 & $44(14.5)$ & \\
\hline Yes & 49 & $7(14.3)$ & & 203 & $87(42.9)$ & \\
\hline Depression & & & -0.51 & & & $-4.26^{* * *}$ \\
\hline No & 62 & $8(12.9)$ & & 185 & $28(15.1)$ & \\
\hline Yes & 88 & $14(15.9)$ & & 321 & 103 & \\
\hline
\end{tabular}

${ }^{*} \mathrm{p}<0.05,{ }^{* *} \mathrm{p}<0.01,{ }^{* * *} \mathrm{p}<0.001$. BMI: body mass index, NK: North Korea, SK: South Korea 
Table 3. Gender differences in factors associated with suicidal ideation

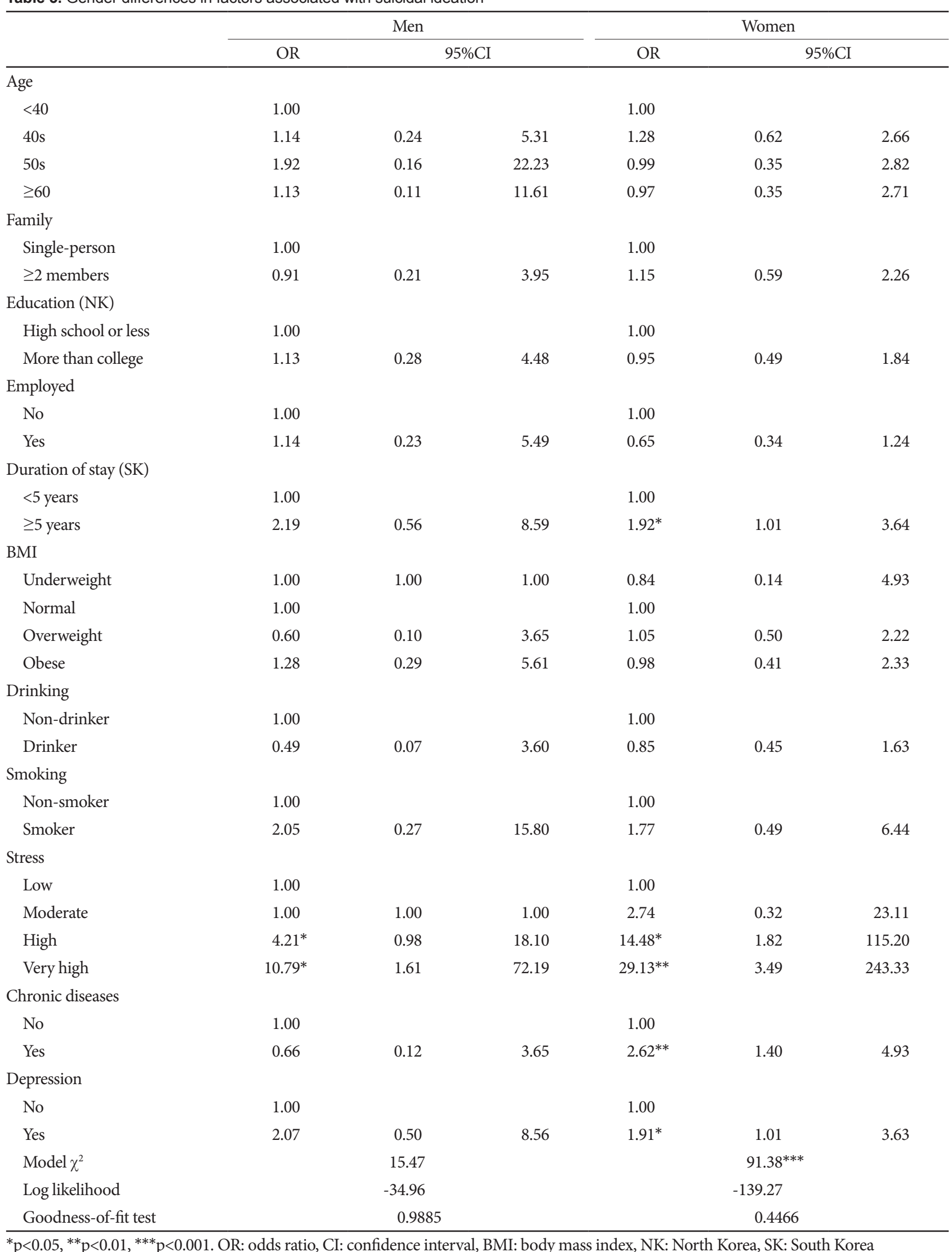

${ }^{*} \mathrm{p}<0.05,{ }^{* *} \mathrm{p}<0.01,{ }^{* * *} \mathrm{p}<0.001$. OR: odds ratio, CI: confidence interval, BMI: body mass index, NK: North Korea, SK: South Korea 
was about three times higher, and those diagnosed with joint and mental health diseases were double those among refugee men. Consistent with the previous study, except for liver disease, refugee women in our cohort reported higher rates of diagnosed chronic diseases than men (data not shown). This gender disparity in the prevalence of chronic diseases could be a result of a lack of knowledge related to health, employment instability, difficulties with social adaptation, and financial burdens among refugee women. As a result, health problems, decreased quality of life, and limited economic productivity might be more prevalent among NKR women.

Our results also showed that refugee women who had been in South Korea for more than 5 years were more likely to think about suicide than those who had recently immigrated to South Korea. Furthermore, women having depression tended to have suicidal ideation. Depression is an important predictor of suicidal ideation. Previous study showed that $90 \%$ of suicide victims had some form of mental health issue, with major depressive disorder comprising $60-70 \%$ of these cases. ${ }^{24}$ Previous study suggested that NKRs who had stayed longer in South Korea had a significantly higher risk of depression. ${ }^{25}$ Thus, depression could be a mediator in the relationship between suicidal ideation and duration of residence in South Korea. However, another study of Vietnamese refugees observed that refugees who had stayed longer in host countries were less likely to experience mental health disorders. ${ }^{26}$ These differing results suggest that further research is needed to investigate whether this inconsistent finding is due to unique characteristics of the North Korean refugee population.

This study has some limitations. First, our main dependent variable was estimated via a single question, which could not fully reflect the NKRs' diverse perspectives and opinions regarding suicidal ideation (including the frequency and intensity of suicidal ideation). Thus, further studies are needed to develop better tools for evaluating suicidal ideation in this population. Another limitation was that our cohort might not represent the whole NKR population, because we recruited participants who voluntarily visited our hospital for medical examinations. However, the demographics of our NKR sample were similar to those of the whole NKR population living in South Korea in terms of gender ratios, age distribution, duration of residence in South Korea and transit countries, and region of origin in North Korea (data not shown). Third, because our data were obtained from a single visit, follow-up assessments are needed to investigate changes in suicidal ideation among NKRs. Despite these limitations, the present results are significant in that we identified gender differences in suicidal ideation and related factors among NKRs in South Korea.

\section{Acknowledgments}

This study was supported by a grant of the Korean Mental Health Technology R\&D Project, Ministry of Health \& Welfare, Republic of Korea (HM15C1054).

\section{REFERENCES}

1. Um MY, Chi I, Kim HJ, Palinkas LA, Kim JY. Correlates of depressive sumptoms among North Korean refugees adapting to South Korean society: the moderating role of perceived discrimination. Soc Sci Med 2015;131:107-113.

2. Kim HH, Lee YJ, Kim HK, Kim JE, Kim SJ, Bae SM, et al. Prevalence and correlates of psychiatric symptoms in North Korean defectors. Psychiatry Investig 2011;8:179-185.

3. Korea Hana Foundation. 2014 North Korean defector's social survey. Seoul: Korea Hana Foundation; 2014.

4. Statistics Korea. Social Survey 2014. Daejeon: Statistics Korea; 2014.

5. Ferrada-Noli M, Asberg M, Ormstad K, Lundin T, Sundbom E. Suicidal behavior after severe trauma. Part 1: PTSD diagnoses, psychiatric comorbidity, and assessments of suicidal behavior. J Trauma Stress 1998; 11:103-112.

6. Kinzie JD, Tran KA, Breckenridge A, Bloom JD. An Indochinese refugee psychiatric clinic: culturally accepted treatment approaches. Am J Psychiatry 1980;137:1429-1432.

7. Sundaram V, Qin P, Zøllner L. Suicide risk among persons with foreign background in Denmark. Suicide Life Threat Behav 2006;36:481-489.

8. Hagaman AK, Sivilli TI, Ao T, Blanton C, Ellis H, Lopes Cardozo B, et al. An investigation into suicides among Bhutanese refugees resettled in the United States between 2008 and 2011. J Immigr Minor Health 2016;18:819-827.

9. Pompili M, Sher L, Serafini G, Forte A, Innamorati M, Dominici G, et al. Posttramatic stress disorder and suicide risk among veterans: a literature review. J Nerv Ment Dis 2013;201:802-812.

10. Kraeh A, Froese FJ, Kim SG. Does socio-cultural and psychological adjustment influence physical health? The case of North Korean refugees in South Korea. Int J Intercult Relat 2016;51:54-60.

11. Kim JY, Choi KH, Chae JH, Hwang HJ. Life stress, social support and suicidal ideation of North Korean refugee women in South Korea. Korean J Soc Welfare Stud 2013;44:33-56.

12. Chin YR, Lee HY, So ES. Suicidal ideation and associated factors by sex in Korean adults: a population based cross sectional survey. Int J Public Health 2011;56:429-439.

13. Park E. Suicide ideation and the related factors among Korean adults by gender. J Agric Med Community Health 2014;39:161-175.

14. Lee YH, Lee WJ, Kim YJ, Cho MJ, Kim JH, Lee YJ, et al. North Korean refugee health in South Korea (NORNS) study: study design and methods. BMC Public Health 2012;12:172.

15. Cho MJ, Kim KH. Use of Center for Epidemiologic Studies Depression (CES-D) scale in Korea. J Nerv Ment Dis 1998;186:304-310.

16. Beck AT, Kovacs M, Weissman A. Assessment of suicidal intention: the Scale for Suicide Ideation. J Consult Clin Psychol 1979;47:343-352.

17. Beautrais AL, Wells JE, McGee MA, Oakley Browne MA; New Zealand Mental Health Survey Research Team. Suicidal behaviour in Te Rau Hinengaro: the New Zealand Mental Health Survey. Aust N Z J Psychiatry 2006;40:896-904.

18. Borges G, Benjet C, Medina-Mora ME, Orozco R, Nock M. Suicide ideation, plan and attempt in the Mexican adolescent mental health survey. J Am Acad Child Adolesc Psychiatry 2008;47:41-52.

19. Forkmann T, Brähler E, Gauggel S, Glaesmer H. Prevalence of suicidal ideation and related risk factors in the German general population. J Nerv Ment Dis 2012;200:401-405.

20. Lee JI, Lee MB, Liao SC, Chang CM, Sung SC, Chiang HC, et al. Prevalence of suicidal ideation and associated risk factors in the general population. J Formos Med Assoc 2010;109:138-147.

21. Fergusson DM, Woodward LJ, Horwood LJ. Risk factors and life pro- 
cesses associated with the onset of suicidal behaviour during adolescence and early adulthood. Psychol Med 2000;30:23-29.

22. Kahng EJ. Factors related to suicide ideation by age group. Health Welf Policy Forum 2005;107:81-86.

23. Yoon IJ. Social adjustments of North Korean migrants and measures to facilitate their resettlement. J Asiat Stud 2007;128:106-143.

24. Goldney RD. A global view of suicidal behaviour. Emerg Med 2001;14:
24-34.

25. Cho YA, Jeon WT, Yu JJ, Um JS. Predictors of depression among North Korean defectors: a 3-year follow-up study. Korean J Couns Psychother 2005; 17:467-484.

26. Steel Z, Silove D, Phan T, Bauman A. Long-term effect of psychological trauma on the mental health of Vietnamese refugees resettled in Australia: a population-based study. Lancet 2002:360:1056-1062. 